\title{
Expertise as Evidence and the Appreciation of the Expert's Opinion
}

\author{
Prof. Asoc. Dr., Fatmir Tartale \\ Phd. Candidate, Gerti Tartale \\ Albanian University, Department of Law and Political Science, Tirana, Albania \\ Email: fatmirtartale@gmail.com
}

Doi:10.5901/ajis.2015.v4n2s2p268

\begin{abstract}
Just like any other source of proof, the expert is estimated in accordance with certain basic rules of procedural law normspenal. According to article 152 of the Criminal Procedure Code, this estimate is made by the court upon conviction interior formed after reviewing the evidence as a whole. Expert opinion is included in its two moments content related and closely interdependent between them: 1) verification of the respective conclusion drawn by the expert with other evidence collected in the case and 2) analysis of expert opinion on the basis of scientific theses verification implemented by the expert in the examination of subject expertise and materials in accordance with the verification of determining the accuracy of the conclusion drawn by the expert compared tasks solved.
\end{abstract}

Keywords: Procedural law, Penal- norms, Criminal Procedure Code

\section{Introduction}

The expert's opinion, like any other evidence is subject to review and there is no defined value (Article 152 of the Penal Procedure Code). This sense, he does not have any special legal nature to be considered as a source of data safer the sayings of the defendant, the witnesses, victims etc. Expert evidence differs from other characteristic that he, as a rule, based on the data of science and arises as a result of evidential material collected in the case.

Legal literature position that is held on the expert opinion as evidence is not the same as compared to the statements by the witness, or consider it as the best means of proving or on the contrary as a tool without any value. Thus, H'Eelio writes that "for every judge should be clear that the evidence of witnesses is an assistant tool that cannot be avoided, but that should be applied only in cases where no other means objective character, as documents, the experts etc. Likewise, P.Saraceno, addressing this problem, writes: "The expert Quotes are weak vehicle testing system recognized in law. The law cannot accept that indisputable facts ascertained by eye-witnesses fall the opinion of experts, with the exception of cases where the witness is discredited or suspicion arises in the authenticity of his sayings.

We think that these attitudes are wrong. In the criminal process as a source of good evidence is that vehicle containing facts correct, safe and arises not doubt its validity. Despite not of the same legal nature, the difference that exists between them, as well as witness testimony or statements of expert opinion take the test value when valued in relation to all the other evidence collected in the case, when they are subjected to verification careful, complete and versatile them. No separate test, whether it's giving notice to the witness or established as fact by expert, cannot remain the cornerstone of courts. Me decision as to ensure a scientifically based expert acts often body and the court proceedings Hearing specialists addressed in the science and with the right attitude. This is having much higher rate to be qualified, as deep and differentiated to be knowledge in the field of science and technique, the more there is the possibility of obtaining an opinion as scientifically based, objective and fair. But, from here it cannot be reached the conclusion that no authority, broad knowledge, reputation good or great erudition expert can be a basis for the acceptance of his opinion as to the best, most perfect, final. Probative value of expert opinion is determined not by the official position of the expert, authority and his word in science, but the merits of thought, by thus you full, convincing his forces.

\section{Assessment and expert opinion}

Assessment and expert opinion from an objective position of special importance to also argued as wrong concept 
according to which the opinion of instances "higher" is always full and grounded than that ii instance "lower". Such attitudes faced not rare in investigative and judicial practice, we have also the source of the concept of official position that occupies the expert, the assumption that the highest state body has accepted a priori that the qualified staff and as a result, the authority of They make their opinion whenever given the fair, without controversial. It is not difficult to understand such concepts, based on formal probation theory, are inconsistent with the principle of free evaluation of the test, procedural regulation that any evidence, including expert opinion, cannot be assessed by apriority considerations, the conditions laid down before. Evaluation that expert opinion of the superior should not be given advance probation greater importance than the opinion of a lower instance is defined in a number of decisions of the Criminal College Court Larte.

Investigative work practice has a priority cases of expert opinion be conditioned by the character controller or second feature that expertise, or repeated, based on qualified specialists, must be appreciated by the right of the first one. We believe that these practices are also repeatedly wrong. Despite that expertise ground- realized we feature the first expert, the request to obtain an expert opinion entitled, second expert does not mean that we should not subject to criticism, his assessment from the standpoint of safety. Not excluded the possibility that repeated expertise, as well as the first one to be not convincing, the unmotivated, the conclusions achieved. As noted, one of the main features of expertise is based on the expert examination of the materials submitted by the body court proceeding or attraction based on their analysis of logical conclusions on existence or absence of this or that fact that becomes more important to resolve the case. There are times when you thought that the body appointed perform expertise is unable understanding of the meaning and importance of self examination methods, implemented by the expert and in this sense, they stay out of each evaluation. We think the opinions of this nature are also not right. The proceedings and the court have the right and duty not only to check the logical process followed by the expert in finding and argumentation of this or that fact, but even in detail, to deal with scientific requirements applied by the expert, in order to be convinced of the truth and the merits of expert opinion. If the body or court proceedings are not able to understand the accuracy of the facts found by the expert a decision taken on their basis can not be an act of legitimate and grounded. Before remain as evidence in the case, any judgment must pass through expert evaluation by inner conviction that the body and the court proceedings.

Investigative and judicial practice recognizes the many cases in which criminal proceedings body in the preliminary investigation and the court in judicial review, while critically valued across your opinion of experts including the implementation of screening methods, have guaranteed the detection of real facts, detect The truth in the matter by using, among others, the question of experts, assigning additional expertise or repetition of expertise from one or other specialists who have knowledge in this area and you are called as experts in the case. Given the fact that in the practice of criminal prosecution bodies and judges are not uncommon when during the process of evaluation that expert opinion, different problems arise that require further clarification or verification and opinions (Conclusions) data until then, the need to they are met by other foremost of which are:

a) The question of the expert

b) additional expertise

c) repeated Surveying

\section{The question of the expert}

Criminal Procedure Code, including as grant legal form of a written opinion to the expert (Article 185 of the Criminal Procedure Code) no sanctions at the same time the question of the expert by the proceeding as a means of making the Quotes for ascertainment. With regards to the facts with the relevant procedural adjustment literature often the question arises what is the legal nature of the statements by the expert and the possibility to assess them as a source of evidence. Procedurial-criminal legislation does not provide direct solutions to this problem. Indirectly to some extent, this problem legally regulated in Article 260 of the Criminal Procedure Code of 1951 which, among other things, said that, after giving written the opinion of the experts, these "then this can be taken in for questioning". On the question of the expert it has procedural in support who stated that "The investigator has the right to ask an expert in order to clarify or expand its conclusion."

It follows that the question is the result of expert opinion given by the expert, i.e. that it comes in each case upon the occurrence of opinion. The purpose of the question is conditioned by clearing anytime or completion of expert opinion, determination that the new Code of Criminal Procedure does not provide, but which, in our view, is necessary. Meanings and statements by expert treatment as a procedural action that follows as clarification and completion of the opinion given by an expert in that it consists of the content of the statements by the expert lies notice new facts, the data that 
complement the general framework provided by the expert opinion or that illustrate particular aspects unclear the body of the proceeding against the opinion given by him before writing.

Quotes of the criminal process are part of the expert opinion given by him, nursed completion of previously awarded. In this sense, expert or statements have probative value, since in them are present facts, the existence of which allows to judge the correctness of the material realization of examinations object of study, or to clarify the application of general scientific requirements by the expert - The question. The meaning of expert as a procedural action probative value does not mean that it is the source of the test. Article 149 of the Penal Procedure Code to determine the sources of evidence establishes how such resources are: "Reports on the facts and circumstances relating to the offense, was obtained from sources provided in criminal procedural law ..." In these enter resources and expert opinions. So writing out the expert opinion and other types of evidence, expert or statements cannot be the source of the evidence. To obtain this understanding required supplementary examinations. In such cases, additional expertise should be appointed whose results are given except by writing. In expert Quotes may be submitted because of circumstances that serve as the refusal of the implementation of examinations (for free material for conducting the examination, lack of knowledge special or necessary equipment. In these cases it is understood or statements serve as notice additional expert on the impossibility of carrying out the examination and the opinion given.

Procedural-criminal legislation does not define what is the position of expert on the occasion of his question by the proceeding. We think that in such cases the expert shall have the duty to appear at the proceeding body to give explanations about the act of expertise and questions addressed by the proceeding. The question of the expert must find its fixing in the minutes of the question that the expert. If the body realizes this action proceeding in a verbal way, the expert has the right not to answer questions of the body to the proceedings, while court questions the participants court or judicial hearing, if, in the opinion of the expert, answers to these questions must be submitted in writing and cannot respond without checking the documents, he cannot answer but requires time to give his opinion to submit in writing to wonder when the next session, to submit it in writing (Article 185 of the Criminal Procedure Code. 363) and as to present, giving his opinion may be subject to questions of the parties under the principle of cross-examination (cross-examination) .Although as the appointment of expertise as well as the question of expert opinion data versus follow the same purpose, they are not the same actions. Therefore, it is wrong attitude that is held in several cases in the practice of the proceedings and judicial authorities in cases where the act of expertise administered without being heard expert evidence and not subject to review by the parties and by the court. As mentioned above that question comes expert after being formulated act of expertise and be given expert opinion. Seeing the problem from the perspective of call unfair position that is held in some cases investigative practice according to which the expert may be questioned by the quality, without considering the decision on the appointment of the expert. Such an approach has no legal basis, because the specialists of a particular field of knowledge called expert on the issue only after his appointment as experts under certain procedural order.

When we participated examination specialist investigation, which is not officially defined by the quality of expert, according to the specific circumstances of the issue found during the inspection, the body of the proceedings and the court may ask that the quality of the witness, but not the quality of the expert . If we insight participated appointed expert in the case, his question the quality of the expert can only take place after the submission of the expert for clarification, fulfillment and given concrete opinion.

\section{Complementary expertise}

Procedural-criminal legislation does not provide for conducting additional expertise, as provided for in Article 26 of the Criminal Procedure Code of 1981). We new Code Pr. Penal not determined in which cases and for what purpose carried out complementary expertise. However, investigative and judicial practice has recognized that we are faced with a similar action when necessary in criminal proceedings in clarifying the specific conclusions of the expert or the giving of thought to new problems. The new Code of Criminal Procedure does not provide additional expertise, such as the Criminal Procedure Code has previous or as the Criminal Procedure Code of Federal Germany in Article 83 thereof which provides that "the judge is allowed to order a new conclusion by the same or other expert, if he considers the act of presenting incomplete") Performance of an additional expert does not mean that the first to be evaluated as an action not good quality. Additional expertise is conditioned by requirements that often in the process of investigating the case, following the appointment of the expert first before investigators need to complete the questions set forth in decision new questions. And if we consider that the process of examination of the materials submitted for expert review requires, in some cases, a relatively long time, during which the body of the proceeding determines facts and previously unknown 
circumstances, the need to perform an additional expert is necessary. Expertise presented with that additional thought is determined when given justice against solved problems arise not any doubt, but it is required to completion or clarification. Additional expertise in this sense is a continuation of the first expert performed a particular action that gives complete solution so versatile and problems that require special knowledge of specific areas of additional knowledge. Expertise is an action that is conditioned by an objective basis. He realized in all those cases where the validity of the conclusions drawn or description of the examinations carried out do not provide the opportunity to realize a versatile estimate of additional achievements. Expert conclusions should not breastfeeding, and, more so, to be replaced with question expert. The difference between them is essential. Complementary expertise, as noted, is a complementary action examination was carried out to give a supplementary opinion on the outstanding new problems, on the contrary, the question of expert across your own preserves in clarifying the opinion given by the expert. Investigative and judicial practice shows that additional expertise is carried out by the same expert who conducted the first expertise. Meanwhile, this order is not categorical. It is entirely possible that, as a procedural action, additional expertise should be implemented also by other experts. This is under the specific circumstances of the case, the special knowledge required versus new problems for solution. In addition to that you raised any other procedural action, additional expertise carried out on an objective basis, in any case it should during reasoned and It reasoned that only so he can serve the purpose for which it is assigned .. its realization at random, according to subjective evaluations body or court proceeding is an action that does not serve the process of investigation, observation and explanation of facts necessary for a fair resolution of the matter the case. It takes its merits, let us illustrate with the example of investigative practice.

We issue the defendant $\mathrm{S}$, charged with embezzlement of state property, the appointment of additional expert investigator wrote inter alia: "In order disclosure of forgery bill, in May 1979 was appointed graphic expertise. Despite the questions raised for solution, their determination was not complete. The investigator has limited the examination of the material submitted for expert analysis only data writing quantity, price and article. During further investigation of the issue, it was found that the supply is storage rooms not given that the same product is registered as incoming twice the same thing that raises invoice verification request the text of the document, concerning the date of delivery of goods, to be determined in that we are dealing with the same amount of supply within a date or at different times. By not giving solution to the problem, the expert has given incomplete thought. Therefore, for clarification of the case comes the need for additional expertise") conducted complementary expertise gave opportunity to clarify body proceedings so complete and versatile CONDITIONS unknown to the issue related to the movement of goods, arguing that we are dealing with a recording that did not respond to the goods. Expertise real additional supply can be accomplished through the initiative of the body or court proceeding, as well as that of the defendant or his lawyer and other participants in criminal proceedings, but in any case, it should be argued, relying on the objective circumstances of the case, the necessity of its implementation in view of the determination or clarification of a fact that becomes more important to resolve the issue. Acceptance or rejection of the request of the defendant and other participants in the process to complete the expertise, should be in any case the result of the justification of the decision of the procedural order to carry. In additional expertise is the same as for any expertise. In any case it must be accompanied by: a) making a decision on the allocation of additional expertise, b) the recognition of the defendant or his lawyer with the decision taken and its settlement requirements, c) implementation of the decision taken for assignment complementary expertise, transferring the expert or submitted it to the relevant institution.

\section{Surveying repeated}

Criminal procedural predict rates of new expertise. In Article 26 of Criminal Procedure Code. in 1981 foresee that, when deemed necessary expertise can be ordered new "), and in article 179 / II of the year 1995 Criminal Procedure Code is determined that: If the expert declared invalid the proceeding takes measures, where necessary, new tasks entrusted to another expert ".Theory and practice of investigative and judicial bodies have agreed that the action should first understand expert laying of the same questions that have been presented at the first expertise, provided that in the second expert to be qualified. In content, this expertise is as a repeated action. Notwithstanding that Article 26 of the Criminal Procedure Code of 1981 and section 179 of the Criminal Procedure Code of 1995 and call this expertise "new"), the practice, giving a more precise definition, called .Si repeatedly that expertise base for repetition of expertise can serve as the factual circumstances of the character, as well as circumstances of procedural character. As factual circumstances character, according to which the body of the proceeding has the right to disagree with the opinion of the expert, can serve: a) the application of expert methods suspicious or improper examination of the material, or when there grounds to doubt about the validity of conclusions, b) mismatch of the conclusions reached by the expert of the issue of found 
materials in the process of investigation, c) Overcoming the powers recognized expert by law. In circumstances procedural nature, on the basis of proceedings which body has the right to renew expertise can be: a) violation of procedural rights recognized the defendant, b) the quality of the statutory withdrawal of persons, that under Article 185 of the Criminal Procedure Code exempted take participate in criminal proceedings and judicial review of the case. Expertise repeated, having in its core without an opinion based on the expert or a dubious opinion regarding its authenticity, accomplished not by the previous expert, but the expert or the Other experts. Strictly adhering to the rule is a necessary condition not only to declare unfounded the first expert opinion, but also to get an idea that respond to objective reality, concrete factual circumstances to be that expert has noticed. Duties repeated realizes expertise includes not only those questions that have been subjected to expert study first, but in a number of cases and questions concerning the need for analysis that justice and full mannered methods that are implemented during the performance of the first expert. Particular expertise in the setting of repeated takes no competence mannered explanation of certain expert ago. This is a fundamental requirement, since it is known expertise exercised in view of the determination or clarification of facts by a special person who has special knowledge in the field of science, so that its competent non being by professional may lead to wrong conclusions .From the content of Article 185/2 of the Code of Criminal Procedure then "When certain experts are more than one and have different opinions each separate act sets out his opinion." This procedural requirement can serve as a basis for assigning expertise repeatedly in different cases where expert opinions are such as to put in doubt the merits and justice of the conclusions of the expert withdrawals. Repeatedly assigning special importance to take the question of expert that has conducted the first expertise. Question aim clarify issues such problems as: a) the validity of the method followed by the expert during the examination of the material, b) observance of objectivity during the examination of a concrete object, c) the basics that have served to achieve given expert conclusion. To these three directions, assumes special importance of faith formation organ examination proceedings that have been subject those materials that are sent to examination. As any other procedural action repetition of expertise carried out on the basis of a reasoned decision of the competent body or the court proceedings, in which must be submitted the reasons for the rejection of the expert opinion given by the need of setting the new expertise, repeatedly.

How important is the reasoning of the decision, let's look at this case to practice criminal proceedings in Tirana. In criminal proceedings charged to G.XH. etc., accused of careless treatment, provided as a criminal offense under Article 96 of the Penal Code. By the prosecution had taken two decisions to perform expertise and were conducted two experiments and the experts were given and their thoughts but that according to the conclusions of the expert groups clashed with each other, where each group of experts raised the violation of the accused, and one does not reveal a violation of treatment, therapies and interventions. When the criminal proceeding was completed, the prosecutor presented the decisions and acts of expertise. The defendant and the prosecutor asked to do new expertise, not only that it was a violation of Article 179 of the Criminal Procedure Code, Article 2 thereof, for notification of the defendant's defense, for the decision, experts and other rights this procedural provision recognizes that, but also the legal obligation that had the body to make the proceedings under Article 179/1 of K.Pr.P. new expertise since the first two were made in violation of the law and that their conclusions were inaccurate suspicious. The prosecutor did not respect the requirements of the new law on expert analysis and sent for trial. The court on the request of the defense and the prosecution itself, appointed new expertise, reflecting the 10 questions of the defense, the prosecution and two for the experts requested by both parties. New expertise gave conclusion that there were no enforcement before medical rules, since they were implemented therapies necessary corollary operations were the treatment of the patient, the treatment was correct and that death can happen in any clinic in the world. So this new expert analysis carried out by qualified specialists, gave a conclusion which was awarded in relation to all the other evidence from the prosecution and the court to judge it objectively for the guilt or innocence of the accused. From the example shown out how special importance gets repeated expert when this is motivated. Was built what was set out that the material existence of the case the first expert opinion, the reasoning of the decision on the appointment of an expert to New and repeat the act of expertise are three moments that provide opportunities for Priority analysis and evaluation broader based and comprehensive view provided by the expert. In investigative and judicial practice often raises the question whether the conduct of expertise repeatedly made mandatory in every case when it first gave opinions that create doubts in the accuracy of findings. To make new expertise and Criminal Procedure Code Greek (Article 197) and in the Russian Criminal Procedure Code) is essentially the organ of the proceeding have doubts about the accuracy of the conclusions of the expert. We think that In each case proceeding body disagrees with the opinion of the expert, he must appoint a new expertise. Certainly, from the standpoint procedural-criminal repetition of expertise is not mandatory action. Article 179/1 of the Criminal Procedure Code to fix this problem, states that "If the expert declared invalid, the proceeding shall take measures, where possible, that new tasks entrusted to an expert to another, i.e. that repeated expertise is in any case an action that remains in the faculty of organ 
proceeding in his right whether to perform or not. Meanwhile, I looked at the content of his problem, it must be stated that in any case that the body of the proceeding disagrees with the first expertise, expertise repeated be performed. Any other attitude is contrary to the reasoning inevitably lead cannot we explain the circumstances objectively the case. Expertise new set when substituted previous expert in accordance with the requirements of Article 186 of K.Pr. Penal. The act of expertise is a procedural document of a legal action to perform. In this sense, Grounds of thought and realization of new expertise cannot lead to the destruction of the act of expertise. As of procedural document of a procedural action to perform, he must join with other materials wherever administered in case.

\section{Main directions of expert evaluation of opinion in the proceeding and the court}

Assessment and expert opinion is a logical move with broad aspect of the character of a special and general. The content of this activity generally stay two closely related moments between them: he legality of the thought, or the observance of procedural norms in the appointment and development of expertise, understanding of the activity of the body and the court proceeding legally to the problem and that the merits of the evidence or factual data required for justification of thought.

1. Analize respect to certain procedural order for the development of expertise, above all demands by the agency and court proceedings to show caution regarding the materials have been made available to the expert, in the sense whether or not these have been sufficient to formulate an opinion.

Practice shows that the known cases where expert opinion criminalist displayed on completion of the text of a document by a certain person, by examining the script on the basis of models received under the dictates of the body to the proceedings and not the so-called free models of writing. In other cases, the errors in the expert opinions have been conditioned by the fact that the models free script, although expert have been introduced, these are designed not at the time of preparation of the document examination, but a few years earlier or later. During this time writing, under the influence of factors has changed, it may have undergone substantial changes. In some other cases, it examined the text of the document that is so short as that expert is unable to realize comparative tests, which exclude the possibility of the formulation of an opinion of the expert realizes certainty. You can be born no doubt of scientific point of view, at a time when expert opinion be not fair, when underwent examination not appropriate objects or materials submitted for examination to be insufficient, you cannot determine the quality or characteristics required from being recognized.

2. Procedural-Criminal Law (Article 149 of Penal Code) provides that evidence obtained from sources provided in the law and evidence during the evaluation that the court must take into account the requirements of the law. For implementation of this provision it is necessary to clarify whether or not the requirements violated the criminal law related procedural-detection and fixing of the evidence and, if these violations are allowed, then it must be determined to what extent they have influenced or may interfere with the detection of full and safe to circumstances procedural case. Violation of criminal law, allowing longer performing expertise, not always entails mistakes in getting expert opinion. Meanwhile, significant violations of procedural order to perform expertise, may affect the realization of an expert not full, comprehensive and objective and conclusions of such an expertise for one of these reasons, despite the fact that from the outside it seems convincing, it must not be accepted by the body and the court proceedings as evidence.

Procedural violations of criminal law relating to the performance of expertise are different, but the main ones can be: a) the performance of expertise of persons who by law must be excluded (Article 181 of the Criminal Procedure Code), b ) violation of a procedural order relating to the delivery of material for expertise, as a result of that quality are not subjected to appropriate examination facilities, c) perform examinations in whole or in part, by persons who are not certain, duly appointed legal, as experts in the matter, d) removal of the defendant from participation in expertise on the basis of deprivation of his procedural rights, recognized by Article 179/2 of the Penal Procedure Code.

3. An important requirement relating to the performance of expertise is the realization of examinations in full. Violation of this requirement inevitably leads to lack of observation and explanation of the facts that are important for full case. Achievement of so long forensic examination is under direct the use of different methods of examination, meeting one other and involvement in examination of all material sent to expertise. Experience shows that in the field of forensic examinations, expert testimony presented in a number of cases, incomplete because only limited expert forensic data to scrutiny than to the body without taking into consideration when formulating the opinion of the examining data to specific fields of knowledge (chemistry, history, bacteriology, etc.). Practice and judicial investigation also shows that we are faced with incomplete examinations when the expert has not fully exploited so All material submitted for examination, when we thought of giving no answer to all the questions, when the work carried out by the expert, which takes important for attracting conclusions, there was not full so we thought given. 
4. Expert source may be evidence in a criminal case when it is proved, i.e. the expert conclusions are based on verified facts very thoroughly and accurately as a result of their examination. The evidence of expert opinion, watched from such an angle, consistent with the concept of fidelity. Preliminary practice and judicial investigation shows that there are cases that the expert conclusions appear shorter, with a single reflection of the substance of the answers, without a scientific grounding their detailed. We think that these conclusions are not acceptable. The body of the proceeding and the court may accept as the source opinion evidence only when the conclusions drawn are scientifically argued.

The importance of the merits of the expert opinion directly related to the duties of the criminal process. Expert conclusions cannot be used by the body and the court proceedings as means of proving the existence or lack of offense, guilt or innocence of the defendant and any other circumstances that becomes more important to resolve the matter right, while these organs are not They are convinced of the merits. Based on expert opinion is a complex concept. But in any case it must keep its contents explanation of these problems: a) the scientific basis of its construction expertise, b) expert opinion basing on the data of science and special expert knowledge, $c$ ) the implementation of effective methods expert examination, the contemporary requirements of science and technique, d) determination of connection with the expert conclusions of the examination methods and the construction of thought on the basis of their results, d) adequacy material object for attracting examination conclusions, f) accuracy of intelligence and expert evaluation of the characteristics and qualities of objects that have been subjected High Examinations. The court in many of its decisions has raised the demand for not allowing the practice where scientific thought the expert received credible entirely without an analysis of its necessary, guiding the district and appellate necessarily verify the scientific basis of the merits. Verifying conclusions that becomes necessary conclusions regardless of the form of their submission, the categorical character of thought, evaluation, according to the expert's view, that the conclusion reached is cut, outside any other interpretation. Despite these estimates, the body and the court proceedings are obliged to settle in that for the expert were not present or scientific basis to arrive at these conclusions, were they legitimate or not if we consider the character of the material that has It was available to the expert, screening methods that have been applied and scientific theses which is such operated. Analysis are always needed to be made. Cannot fair he accepted expert opinion, which contains two sets of facts from which one group argues the merits of thought and another group overthrows it without having clarified in these cases the cause of contradicts. The presence of changes in comparative material often creates the basis to assume the lack of identity.

5. We estimate of expert opinion a particular direction represents professional qualification evaluation expert at the problem, the body and the court proceedings are obliged to by the expert material and other data administered in the case, to verify education expert, experience, experience in working in specialty concrete, narrow specialization within the profession of the expert. Analysis mentioned directions is not a problem without importance. Thus, in the case of the defendant F., the Supreme Court noted that "In the decision of investigators to perform forensic accounting and expert opinion given not shown that what is taken and where works M's at a time that these data are necessary to verify whether he had the right to realize the expertise ... in a case should be clarified whether the appointed expert has special knowledge to perform an accounting expertise, what has he education and experience practical work ".We few regulations specifically set who may be the quality of the expert. So in the Council of Ministers Decision no. 343 Dt. 06/05/1993 "For over reports to the Ministry of Justice of Forensic Expertise Service" in its Article 8 stipulates: "Services performed by expert forensic expertise and expert external functionaries"). While in Decision no 120 dated 27.02.2003 "On the establishment of the Institute of Legal Medicine" article 3 / c ) has been entrusted the task referring to the procedures provided for in relevant legislation, civil and criminal procedural and other laws in force, to carry out forensic expertise, etc. .We fact this government decision is not about external experts, but this is not an obstacle to these experts, to be appointed and to provide scientific opinion, when required by the proceeding, the court or anyone interested, you It needs their opinion, the specialized in the relevant area. when they are licensed in the court, which previously necessarily have training in certain areas of legal medicine. If the conclusion on insufficient qualification of the expert may be withdrawn on the basis of analysis of the data on it, it is in issue, conclusion on the expert qualification enough can be achieved on the basis of recognition, not only data expert person, but also the content of the expert opinion to act, to connect with the path followed by the expert, in the examination of the material and the level of use in the process of carrying out scientific methods expertise. In other words, the conclusion can only be drawn as a result of the evaluation of the scientific merits of thought.

6. Another direction is important for estimating the expert opinion is the realization of expertise from a competent person. This problem arises that when the appointment of the expert. But this does not absolve the body of the court proceedings and the task of returning back to the problem after receiving the opinion of expert. The questions you raised before the expert selected on the basis of scientific knowledge in various branches of science or with the help of various 
scientific methods screening study. This circumstance may not always be kept in mind, with all its merits instance, when the appointment of the expert. After performing the expert presented the opportunity and demand determining the final so that on the basis of which the field of knowledge and concrete which screening methods are found evidence that indicated in the opinion of the expert and whether or not the expert has special knowledge sufficient for the detection of these facts. Appreciation of expert opinion from the standpoint of its competent mannered that includes: a) the study of the questions asked before the expert and include them in this or that field of knowledge, b) study of the data found by the expert and settlement the problem that was asked what special knowledge for their recognition, c) recognition of data that characterize the expert as a specialist in a certain area of science, d) determining whether the expert's competence enter into scientific methods of examination, the practice during performance that expertise. As stated out that guidelines for estimating the opinion of the expert have a large extent. Application carefully, very thoroughly and objectively allows them to reach the right conclusions, conclusions that respond to objective reality, finding truth in the case. Assessment of the expert opinion given by not the goal in itself. For each of the cases, the organ of the proceedings and the court should take one of the following decisions: a) the receipt of expert opinion based full and, while the data are reflected in the accurate and important to the case, b) acceptance of thought not entirely clear and complete and setting, when necessary, to new expertise or expert question for clarification or completion of the opinion given, c) admission of expert opinion or arising unfounded doubts its authenticity and setting when the need arises, to a new expertise or performing other procedural actions in order to verify given opinion.

\section{Reference}

F. Helio Traite de l'instruction criminelle au theorie dy code d'instruction cirminelle,Paris,1945

P.Saraceno La decisione sul fatto incerto nel processo penale,Padova ,1943

Penal Code Descisions - Vendime te Kolegjit Penal te Gjykates Larte 1985-2006

Penal Code Kodi i Procedures Penale Shqiptar ,neni 185,Tirane, 2014

Penal Code - Kodi i Procedures Penale, neni 260,Tirane, 1953

Penal Code - Kodi i Procedures Penale, neni 185e363,Tirane,2014

Penal Code - Kodi i Procedures Penale, neni26,Tirame, 1981

Penal Code - Kodi i Procedures Penale i Gjermanise,neni83,Berlin, 1987

Archieve of Prosecutors - Arkivi i Prokurorise prane Gjykates se Rrethit Gjyqesor Tirane,1979

Penal Code - Kodi i Procedures Penal Shqiptar,neni 26,Tirane,1981

Penal Code - Kodi i Procedures Penale, neni 179,Tirane, 2014

Greek Penal Code - Kodi i Procedures Penale Grek , neni 197,Athine, 1987

Russian Penal Code - Kodi Procedures Penale Rus, neni 13,Moske,1988

Penal Code - Kodi i Procedures Penal Shqiptar, neni 149,Tirane,2014

Council of Ministers Descisions - Vendimin e Keshillit te Ministrave Nr. 343 dt. 05.06.1993 "Per kalimin ne varesi te Ministrise se Drejtesise te Sherbimit te Ekspertimit mjekoligjor" Neni 8

Council of Ministers Descisions - Vendimini Keshillit te Ministrave Nr.120 date 27.02.2003 "Per krijimin e Institutit te Mjekesise Ligjore"neni 3/c 